\title{
An Overview of the Synthesis and Gene Transfer Properties of Triblock Copolymers Poly(2-Methyl-2-0xazoline-b-Tetrahydrofur ane-b-2-Methyl-2-0xazoline)
}

\author{
Bazoly Rasolonjatovo1, Bruno Pitard2, Philippe Guégan1, Hervé Cheradame ${ }^{3 *}$ \\ ${ }^{1}$ Université Pierre et Marie Curie, Laboratoire de Chimie des Polymères, 94200 Ivry sur Seine, Paris, France \\ ${ }^{2}$ Institut du Thorax, INSERM, UMR 9158 Quai Moncousu, Nantes, France \\ ${ }^{3}$ Laboratory LAMBE, University of Evry, UMR 8587, Bld Mitterrand, 91025 Evry cedex, France, Polytheragene, 4 \\ rue Pierre Fontaine, Evry, France \\ Email: ${ }^{\text {herve.cheradame@univ-evry.fr }}$
}

Received 12 January 2014; revised 28 February 2014; accepted 14 March 2014

Copyright (C) 2014 by authors and Scientific Research Publishing Inc.

This work is licensed under the Creative Commons Attribution International License (CC BY).

http://creativecommons.org/licenses/by/4.0/

\section{(c) (i) Open Access}

\section{Abstract}

The synthesis of poly(2-methyl-2-oxazoline-b-tetrahydrofurane-b-2-methyl-2-oxazoline) triblock copolymer of low molar mass has been carried out. Characterization of the purified polymer by ${ }^{1} \mathrm{H}$ and ${ }^{13} \mathrm{C}$ NMR spectroscopies is described. These block copolymers did not give DNA containing polyplexes. The in vivo transfection properties were investigated by injection of tibialis muscles and intratracheal administration of female Swiss mice. These triblock copolymers with a molar ratio [2-methyl-2-oxazoline units]/[tetrahydrofurane units] in the 3 - 5 range gave a higher transfection efficiency than that of Lutrol or of PE6400 which are the gold standards of this transfection technique. Hydrolysis increased the performances of muscle transfection, showing the beneficial effect of the presence of positive charges, but was clearly detrimental to the transfection efficiency of pulmonary epithelium.

\section{Keywords}

Triblock Copolymer; Cell Transfection; Vector; Gene Therapy; Neutral Amphiphilic Block Copolymers

\footnotetext{
*Corresponding author.

How to cite this paper: Rasolonjatovo, B., Pitard, B., Guégan, P. and Cheradame, H. (2014) An Overview of the Synthesis and Gene Transfer Properties of Triblock Copolymers Poly(2-Methyl-2-Oxazoline-b-Tetrahydrofurane-b-2-Methyl-2-Oxazoline). Journal of Biomaterials and Nanobiotechnology, 5, 53-65. http://dx.doi.org/10.4236/jbnb.2014.52008
} 


\section{Introduction}

The expression of therapeutic protein in cells by the introduction of DNA requires its protection by vectors against DNAses [1]. Usually, DNA sequence delivery systems can be classified in two types: viral vector-mediated systems and non-viral mediated systems (mainly synthetic ones). Although viral systems are by far the most effective for gene delivery, their safety, packaging and production issues let them less attractive than synthetic vectors. Thus, synthetic materials have become the most desirable tools for gene delivery in both basic research units and clinical settings. However, using synthetic vectors such as polymer based vectors is far from being a complete success in vivo, not only due to low efficiency but also due to cytoxicity problems highlighted during clinical trials [2] [3]. Moreover DNA delivery into the cells relies on many constraints such as condensation, complexation, endocytosis or crossing through the bilayer lipid membrane, nuclear targeting and expression in an eukaryotic cell. In this context, more particularly, polymer based synthetic vectors offer advantages such as relative simplicity of production, safety and versatility. Macromolecular design is of primary importance in the domain of synthetic vectors for gene therapy. However, up to now their low efficiency comparatively to virus based systems prevented their introduction in therapeutic treatments. Fundamental research was carried out aiming at understanding relationships between their structure and their transfection efficiency, as well as their toxicity [4]. This research involved careful studies of polymer synthesis from the point of view of controlled architecture due to the need of high purity for these polymers to be used in physiological fluids [5] [6].

Two classes of polymers were under investigation, positive polyelectrolytes and neutral amphiphilic block copolymers. One of the preferred positive polyelectrolytes is polyethylenimine (PEI) which offers, for instance, opportunity to be used in the treatment of cystic fibrosis or cancer [7]. These synthetic vectors can be used when cells with negatively charged outer membrane are to be transfected, and it was shown that the linear macrostructure seems to be a definite advantage for DNA transfection for positive polyelectrolytes [4].

Block copolymers, which are the materials of choice of this research, seem to be on the verge to make profit of their outstanding properties. Since the discoveries of the potential of the triblock poly(ethylene oxide-b-propylene oxide-b-ethylene oxide) neutral amphiphilic block copolymers have an important future in the treatment of myopathies by gene therapy [8] [9]. It was rapidly recognized that the potential of these new neutral vectors was linked with their amphiphilic nature having at the same time a hydrophilic and a hydrophobic moiety. The fact that a polymeric system exhibits these last two properties is most of the time related to the blocky macrostructure. Indeed, it is well known that the block copolymers exhibit at the same time the individual properties of each block. It is worth recalling here that these transfection vectors do not exhibit the same properties as the ones of positive polyelectrolytes and behave in a very different way. Moreover, it has been shown for these block copolymers that the in vitro and in vivo efficiencies can be very different and not necessarily correlated. Thus, the research described below is dealing with the more relevant in vivo experiments. Besides the real improvements in transfection efficiency which has already been observed, an important improvement is to be looked for in polymer labeling techniques for cell targeting. These polymeric synthetic vectors may have a future in the treatment not only of genetic diseases but also of cancer diseases [10]. There is still a large place for structure optimization of these polymers of therapeutic interest and high added value. The synthesis by cationic ring opening polymerization of the triblock poly(ethylene oxide-b-tetrahydrofurane-b-ethylene oxide) on which the new more hydrophobic poly(tetrahydrofurane) sequence was replacing the central poly(propylene oxide) block of the above triblocks (poloxamer) allowed studying the in vivo transfection efficiency of this copolymer which was found to be approximately of the same efficiency as that of the one based on poly(propylene oxide) [5] [6].

This observation brought an answer to the question of the relative importance of the two types of sequence involved in the vector. The poly(ethylene oxide) sequence which is of low biodegradability can be replaced by another hydrophilic block. Finally, the synthesis of the triblock poly (2-methyl-2-oxazoline-b-tetrahydrofurane-b-2-methyl-2-oxazoline), already synthesized by Goethals [11], in which both types of sequence were new in the context of DNA transfer, was aiming at the demonstration that the most important parameter for this new type of synthetic DNA transfer agents is the amphiphilic character, the chemical structure mainly governing toxicity. Thus, careful synthesis by cationic ring opening polymerization of this amphiphilic block copolymer and the determination of its physico-chemical properties in physiological conditions was undertaken in order to answer the question of their suitability for targeted transfection [12]. Some of the characteristics of this block co- 
polymer were in favour of DNA transfer properties, as shown by their interactions with model lipidic bilayer membranes, while other characteristics seemed to indicate a low efficiency, as shown by the low DNA complexation ability. In this previous paper, besides the synthesis of the block copolymer poly(2-methyl-2-oxazolineb-tetrahydrofurane-b-2-methyl-2-oxazoline) P(MeOXZ-THF-MeOXZ), some observations, by the technique of black membranes, were reported suggesting that the interactions of the triblock with a model membrane (diphytanoyle-lecithine) were able to induce the formation of transitory holes in the membranes of an average diameter of around $0.7 \mathrm{~nm}$ diameter [12]. It was also observed that a partly hydrolysed triblock, thus positively charged, was more efficient with formation of more permanent holes. The purification technique was also described, and it was recognized the necessity finding experimental conditions for the synthesis of these block copolymers without the production of homopolymers which could spoil the final product.

The present paper brings some more details on the $\mathrm{P}(\mathrm{MeOXZ}-\mathrm{THF}-\mathrm{MeOXZ})$ copolymer in vivo biological properties of these block copolymers as plasmid transfer agents. Muscle transfection was chosen because the range of possible transfer agents is low, Lutrol or poloxamer PE6400 being the most successful agents in the class of neutral polymers for such transfection which could be useful treating dystrophy. It was also known that systemic administration is not adapted to the transfection mode of these neutral vectors. Another type of transfection, by intratracheal administration, was also effected, because the comparison could be a help for better agents to be used in the case of cystic fibrosis.

\section{Results and Discussion}

\subsection{Polymer Synthesis}

Several polymers were synthesized, and four of them have been selected to study their physiological behavior and their transfection characteristics. Their molecular characteristics are shown on Table 1. The fifth sample was obtained from the fourth polymer (Ads0681A) by hydrolysis.

Table 1 shows some examples of triblock synthesis (for experimental data see section IV). It can be seen that the polymerization degree calculated by ${ }^{13} \mathrm{C}$ NMR spectroscopy demonstrated that the poly (THF) unit content was lower than that of 2-methyl-2-oxazoline units.

Polymer ads054 was synthesized aiming at finding conditions for a higher content of THF units. In that case, after quench by methyloxazoline of the THF polymerization, the system was left for 16 hours at room temperature. Then acetonitrile was added so that the MeOX monomer concentration was 2M. 2-Methyl-2-oxazoline polymerization was carried out at $50^{\circ} \mathrm{C}$ for 24 hours and at room temperature under stirring for 2 days. It is to be noted that this polymer which is rich in THF units is not easily dispersible in water. In principle, for gene transfer application, the polymer must be dispersed in physiological media, when systemic injection is to be used. While this requirement is less stringent when a gene transfer application for cystic fibrosis is effected, because the mixture DNA-synthetic vector can be used by instillation or (micro) spraying, sample Ads054 was not further used for in vivo experiments.

\subsection{Molecular Characterization of a Triblock Copolymer Poly (2-Methyl-2-0xazoline-b-Tetrahydrofurane-b-2-Methyl-2-0xazoline)}

The determination of the molar mass was difficult. The main techniques were ${ }^{1} \mathrm{H}$ and quantitative ${ }^{13} \mathrm{C}$ NMR spectroscopy. Adventitious absorption on columns prevented the obtention of a reliable value for the molar mass by SEC. The determination by NMR spectroscopy using sequence tags can afford quantitative informations. On ${ }^{1} \mathrm{H}$ spectra, several tags can be used: It was reported above that after THF polymerization, the medium was quenched by oxazoline monomer so that the living pTHF was terminated by an oxazolinium cation the content of which can be determined on the spectra. This tag attached to the poly(THF) chain ends was used giving a way to the determination of the polymerization degree of the THF block. An example is given in Table 2. The same determination can be carried out on the final triblock before quench. However, it was found that this determination was too much sensitive to the necessary workup, generally giving too high values for the polymerization degrees due to oxazolinium degradation, and it was more accurate to quench the final oxazolinium containing oligomer by sodium hydroxide. This oligomer gives a ${ }^{1} \mathrm{H}$ spectrum on which the terminal $-\mathrm{CH}_{2} \mathrm{OH}$ content, peak at $3.7 \mathrm{ppm}$, or the $-\mathrm{CO}-\mathrm{CH}_{3}$ content (belonging to the terminal oxazoline unit), peak at $2.1 \mathrm{ppm}$ can be measured (Figure 1). On the other hand, on the final triblock, the ${ }^{13} \mathrm{C}$ spectrum shows the small peak at 21.2 
Table 1. Molecular characteristics of triblocks poly(2-methyl-2-oxazoline-b-tetrahydrofurane-b-2-methyl-2-oxazoline).

\begin{tabular}{ccccc}
\hline $\mathrm{N}^{\circ}$ of the polymer & $\begin{array}{c}\text { Molar ratio poly(2-MeOx) } \\
\text { units to poly (THF)units } \\
\left({ }^{1} \mathrm{H} \text { NMR). }\right.\end{array}$ & $\begin{array}{c}\text { Molar mass (Da) calculated } \\
\text { from the oxazolinium } \\
\text { content }\left({ }^{1} \mathrm{H} \text { NMR). }\right.\end{array}$ & $\begin{array}{c}\text { Molar mass (Da) using the peak } \\
\text { at 23.2 ppm on }{ }^{13} \text { C spectrum } \\
\text { after purification. }\end{array}$ & $\begin{array}{c}\text { DPn of the } \\
\text { poly(THF) block }\end{array}$ \\
Ads052 & 5.2 & 3300 & 4000 & 7.75 \\
Ads045 & 3.64 & $1600^{*}$ & 2000 & 5.2 \\
Ads054 & 1.35 & 6800 & 6400 & 16 \\
Ads0681A & 4.3 & 4500 & $3800^{* *}$ & 8.6 \\
AdsO681B ${ }^{* * *}$ & 4.3 & - & 3200 & 8.6 \\
\hline
\end{tabular}

${ }^{*}$ Measured by SEC; ${ }^{* *}$ cf. Table 2 and text. ${ }^{* * *}$ Sample Ads0681A after hydrolysis (38\% hydrolyzed poly(oxazoline) units (see text)).

$$
\text { | }
$$

Triblock copolymer p (2-MeOx-b-THF-b-2-MeOx)

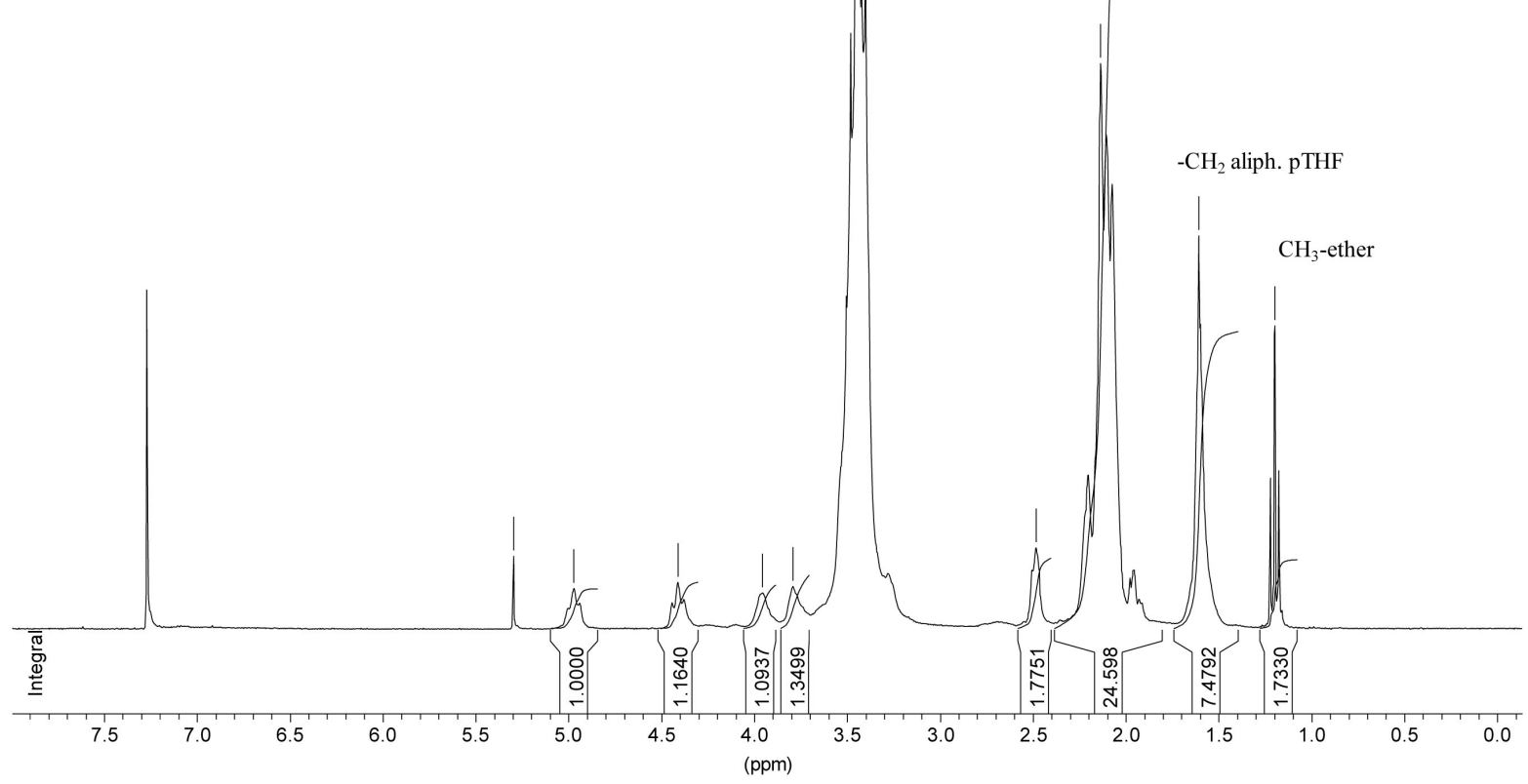

Figure 1. Protonic NMR spectrum of the triblock copolymer p(2-MeOx-b-THF-b-2-MeOx).

ppm which belongs to the "aliphatic type” methylene of the THF unit next to the poly(oxazoline) block (Figure 2). The values given by these determinations can be compared. An example is given in Table 2. On the other hand, the ratio [oxazoline units]/[THF units] of the final block copolymer can be determined on both ${ }^{1} \mathrm{H}$ and ${ }^{13} \mathrm{C}$ spectra. Thus, experimentally it is found that the molar masses can be determined with an accuracy of $\pm 15 \%$.

\subsection{Study of the Hydrolysis of the Triblock Copolymer}

Acid hydrolysis of the triblock can transform partly or completely the oxazoline units into ethylenimine units. The interest of this transformation is to produce monomer units which can be protonated and can transform the polymer into a positively charged polyelectrolyte at physiological $\mathrm{pH}$ [12]. It was interesting to know whether the triblock could be hydrolysed without degradation. The above polymer ads068 was chosen for this study. Hydrolysis was carried out in $\mathrm{HCl}$ aqueous solution at reflux temperature.

${ }^{1} \mathrm{H}$ NMR analysis showed that acid hydrolysis could be carried out without noticeable pTHF degradation. It was shown that the intensity of resonance of the terminal $-\mathrm{CH}_{2}-\mathrm{OH}$ relatively to that of the pTHF (aliphatic me- 


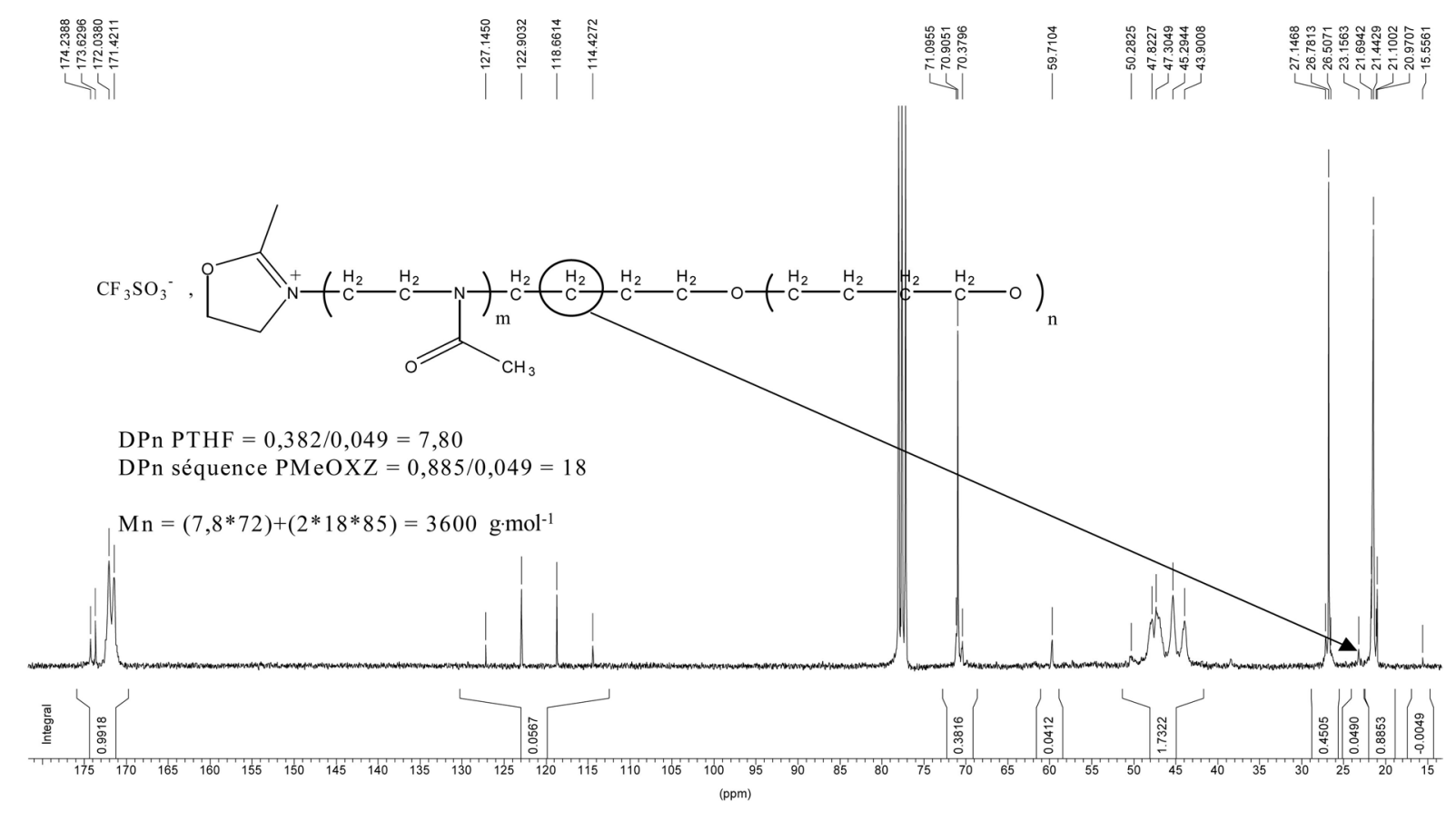

Figure 2. Quantitative ${ }^{13} \mathrm{C}$ NMR spectrum of block copolymer ADS0681A. The molar mass quoted on Table 1 is different (3800 Da) calculated from the averaged polymerization degree.

Table 2. Average number polymerization degree of the PTHF sequence of polymer ads0681A determined by NMR spectroscopy.

\begin{tabular}{ccccc}
\hline $\begin{array}{c}\text { DPn of the pTHF block } \\
\text { from the terminal } \mathrm{CH}_{2} \mathrm{OH} \\
\text { on the } \mathrm{NaOH} \text { treated } \\
\text { precursor. }\end{array}$ & $\begin{array}{c}\text { DPn of the pTHF } \\
\text { block from the terminal } \\
\text { oxazolinium } \\
\text { ion on the precursor. }\end{array}$ & $\begin{array}{c}\text { DPn of the pTHF block } \\
\text { from the terminal } \\
\text { oxazoline on the } \\
\text { precursor. }\end{array}$ & $\begin{array}{c}\text { DPn of the pTHF } \\
\text { block from the peak } \\
\text { at 21.8 ppm on the final } \\
{ }^{13} \mathrm{C} \text { spectrum }\end{array}$ & $\begin{array}{c}\text { Average } \\
\text { DPn of } \\
\text { pTHF block }\end{array}$ \\
\hline 9.8 & 8.6 & 8.4 & 7.7 & 8.6 \\
\hline
\end{tabular}

thylene units) did not change respectively on the spectrum of the non hydrolyzed polymer and the hydrolysed (1 hour reaction time) polymer. It was also checked that, again taking the pTHF units as an internal reference, the sum of the non hydrolyzed (contained in the peak at $3.4 \mathrm{ppm}$ ) and hydrolyzed (peak at $2.7 \mathrm{ppm}$ ) poly(oxazoline) units was constant for the two above triblocks (Figure 3).

Then, the proportion of hydrolyzed oxazoline units was easily calculated from the intensity of the peak at 2.70 ppm ( $\mathrm{N}-\mathrm{CH}_{2}$ - of polyethylenimine units) (Figure 3). It was found that, in the case of Ads0681A, 38\% of the oxazoline units of the polymer were hydrolyzed for $30 \mathrm{~min}$ of reaction time and $58 \%$ for 1 hour reaction time. The hydrolyzed unit content was not calculated directly from the intensity of the peak at $2.1 \mathrm{ppm}$ of the $\mathrm{CH}_{3}$-CO- groups because traces of acetate ions remaining after the polymer workup could spoil the results.

\subsection{Triblock Characterization by Physiological Methods}

It is well known that neutral block copolymers do not give polyplexes, i.e. do not give DNA complexation. The only copolymer which could give interactions with nucleic acids is the hydrolysed one, because it is positively charged. However, even in this case it is doubtful that the charge density would be high enough to give an efficient DNA compaction. This is the reason why this point was not addressed in this study. It is known that the absence of DNA complexation does not prevent transfection to be improved by the use of neutral triblocks, as it will be shown below.

\subsubsection{Electrophoresis Assays}

The possible interaction of DNA with polymer ads0681A was investigated. This polymer was chosen as a rep- 


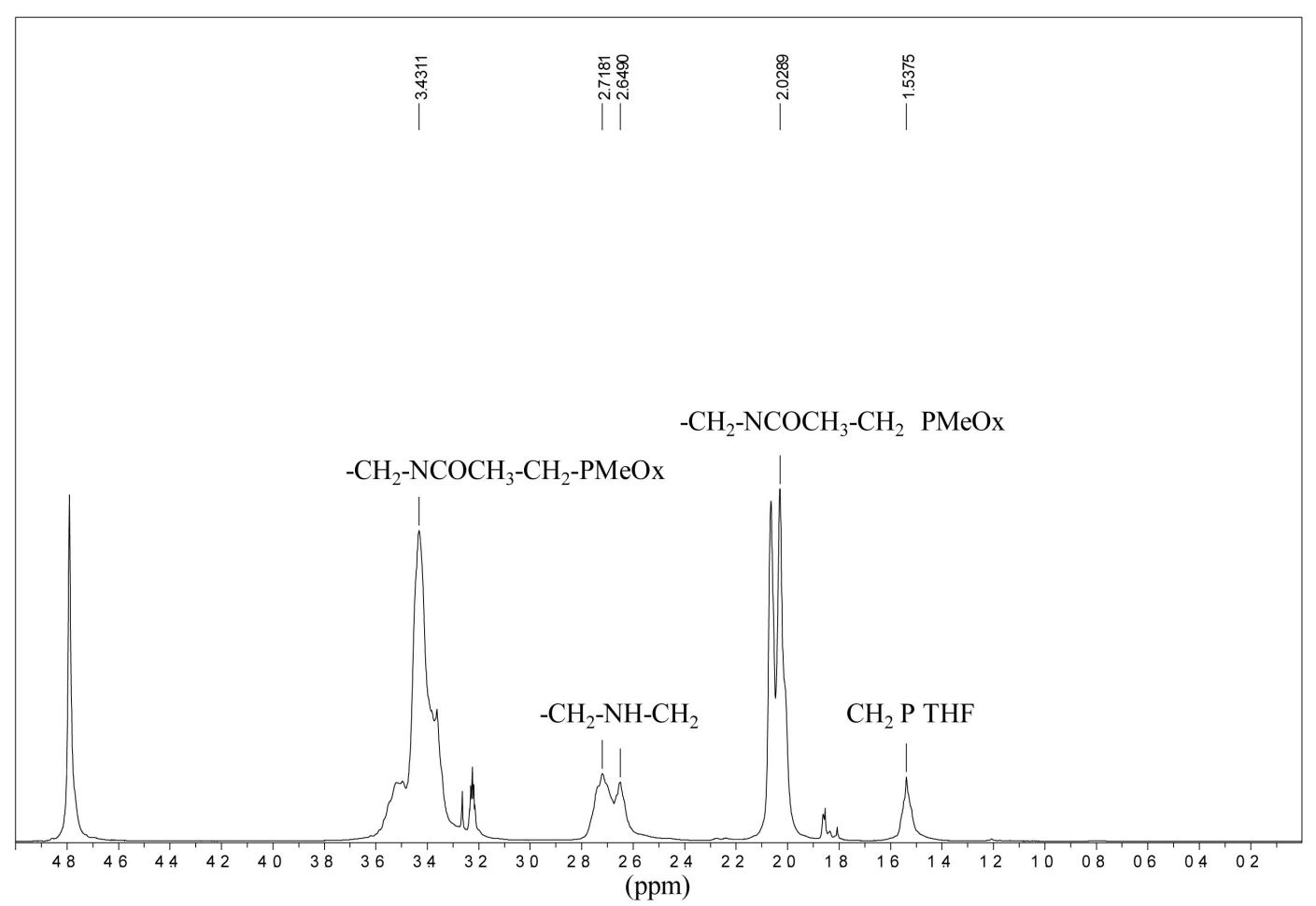

Figure 3. Protonic spectrum of a block copolymer after hydrolysis showing the transformation of a part of the amide functions (38\%) into amine functions.

resentative of the polymers having a poly (THF) content sufficiently low to allow a good dispersability in water. The first technique chosen for this characterization was the study of DNA complexation by electrophoresis. Figure 4 shows some experiments

In this first series of experiments, it is clear that DNA is not complexed neither by non hydrolyzed ads068 (well 4, Figure 4) nor by poly (2-methyl-2-oxazoline) (well 8, Figure 4), as expected from their uncharged polymeric structure. It is also clear that hydrolysis which allows transforming part of the 2-methyl-2-oxazoline units of the polymer into ethylenimine units site for positive charges produces a material which can give complexation with DNA. Polymer which underwent 30 min hydrolysis (38\%) gives a weaker complexation (well 6, Figure 4) than the polymer which underwent 1 hour hydrolysis (58\%) which gave a rather good complexation in these conditions (well 10, Figure 4).

\subsubsection{In Vivo Reporter Gene Delivery}

In vivo assays were affected as follows: $5 \mu \mathrm{g}$ of DNA coding for luciferase were associated to an increasing quantity of copolymer. Mixtures were injected to muscles at a ratio of $35 \mu \mathrm{L} /$ muscle. Injected muscles were Tibialis muscles and 2 mice per mixture, which makes 4 muscles as a whole. After 7 days, animals were sacrified, and the muscles were collected for luciferase content.

The results of the in vivo assays are summarized in Table 3. The potential of various triblocks poly(2-methyl-2-oxazoline-b-tetrahydrofurane-b-2-methyl-2-oxazoline) copolymer/DNA mixtures was assessed for the transfer of plasmid into the tibial anterior muscle, compared to that achieved with PE6400 used as reference in this study. Indeed Lutrol, a polyethylene oxide-polypropylene oxide-polyethylene oxide triblock has been previously shown increasing dramatically the transfection efficiency in skeletal muscle compared to naked DNA. Seven days after injection of triblock copolymers/DNA mixtures, the expression of reporter gene was monitored (Figure 5). Formulation containing Ads52 at 0.05 and $0.1 \%$ led to the highest luciferase expression in mouse tibial anterior muscle. The potential of the triblocks was also evaluated in comparison with a poloxamer PEOPPO-PEO (PE6400) triblock copolymer. The luciferase expression was improved by a factor of 3 compared to that of the poloxamer PE6400. Presence of $0.1 \%$ of the various copolymers gave the optimal luciferase expression and improved the luciferase activity, by a factor in the range 2 - 4, compared to Lutrol (Figure 6). 


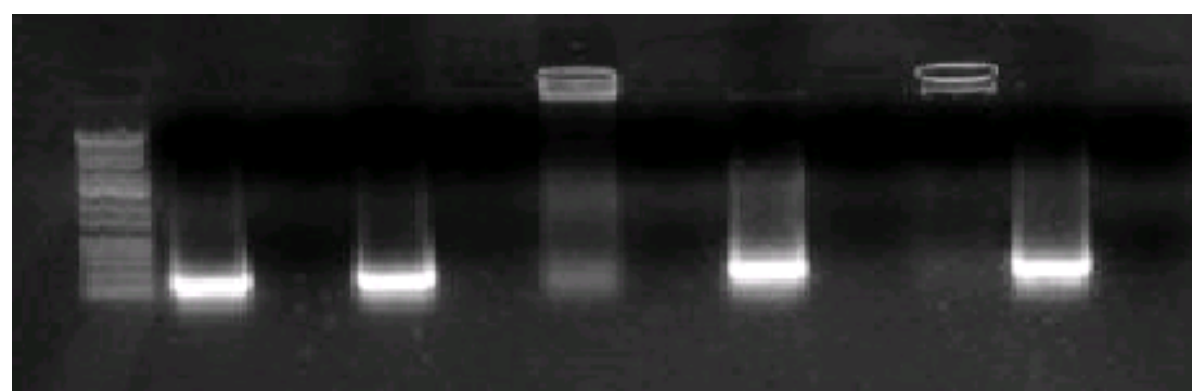

Figure 4. Study of the complexation of DNA (10 $\mu \mathrm{g}) 146 \mathrm{bp}(8 \mu \mathrm{g} / \mathrm{lane})$ by various polymers: from left to right, well 1: DNA ladder; well 2: DNA 146bp alone; well 3 ads0681A alone; well 4: DNA + ads0681A $10 \mu \mathrm{g}$; well 5: ads0681B 38\% hydrolyzed alone; well 6: DNA + ads0681B 38\% hydrolyzed $10 \mu \mathrm{g}$; well 7: poly(2-methyl-2-oxazoline) $\mathrm{Mn}=2600 \mathrm{Da}$ alone 10 $\mu \mathrm{g}$; well 8: DNA + poly(2-methyl-2-oxazoline) Mn = 2600 Da $10 \mu \mathrm{g}$; well 9: ads068 58\% hydrolyzed alone; well 10: DNA + ads068 58\% hydrolyzed $10 \mu \mathrm{g}$; well 11: DNA 146bp alone.

Table 3. In vivo assays, injection of Tibialis muscles of female swiss mice of $5 \mu \mathrm{g}$ of DNA coding for luciferase.

\begin{tabular}{|c|c|c|}
\hline $\begin{array}{l}\text { Copolymer number, and concentration of the } \\
\text { solution for maximum efficiency }\end{array}$ & $\begin{array}{l}\text { Ratio }[\mathrm{MeOX}] /[\mathrm{THF}] \text { monomer } \\
\text { units in the copolymer. }\end{array}$ & Maximum CPS/mg of protein \\
\hline Ads045, (0.1 - 0.5\% w/w solution) & 3.6 & $25.10^{3}$ \\
\hline Ads0681A ( $0.1 \%$ w/w solution) & 4.3 & $44.10^{3}$ \\
\hline Ads052 (0.05\% w/w solution) & 5.2 & $85.10^{3}$ \\
\hline PE 6400 (0.05\% w/w solution) & {$[\mathrm{EO}] /[\mathrm{PO}]=0.87$} & $11.10^{3}$ \\
\hline Ads0681B hydrolysed 38\%, 0.5\% w/w solution & {$[\mathrm{MeOX}$ or $\mathrm{EI}] /[\mathrm{THF}]=4.3$} & $66.10^{3}$ \\
\hline
\end{tabular}

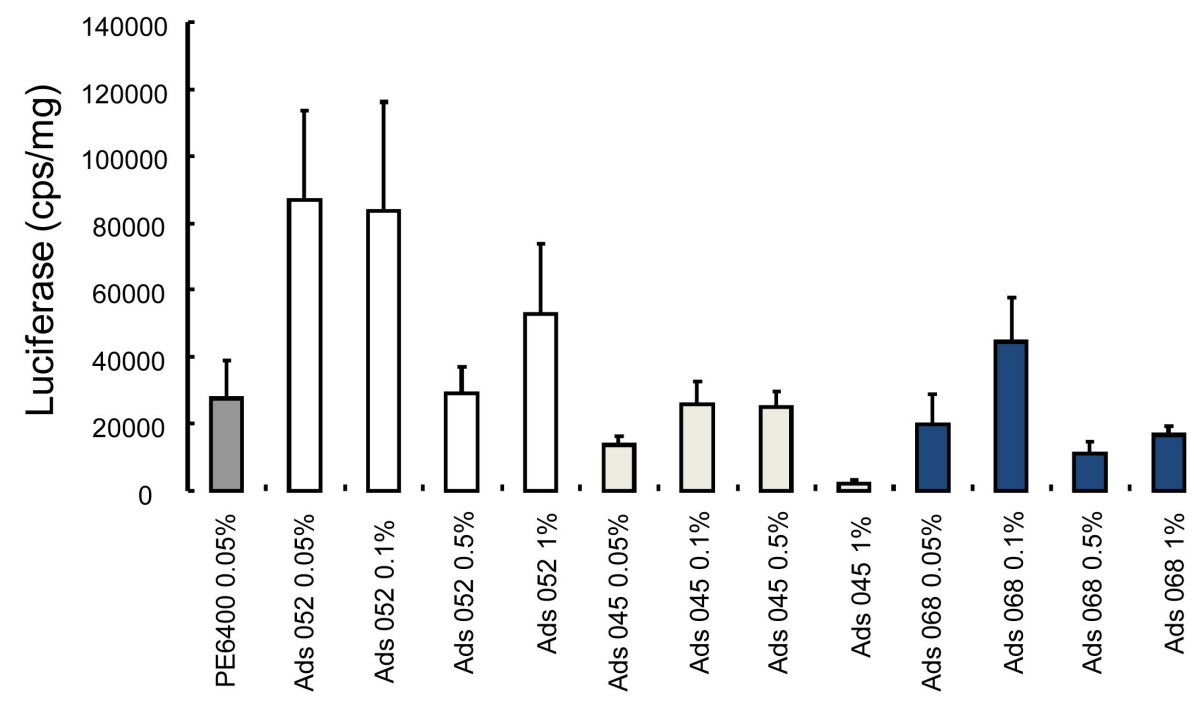

Figure 5. Expression of luciferase in skeletal muscles of swiss mice using various amphiphilic $\mathrm{p}$ (2-methyl-2-oxazoline-b-tetrahydrofurane-b-2-methyl-2-oxazoline) triblocs as vectors, seven days after injection (Ads068 is the non hydrolysed copolymer). Cf. Table 2.

One can see on Table 3 that the higher the ratio $[\mathrm{MeOX}] /[\mathrm{THF}]$ monomer unit in the copolymer, the better is the transfection efficiency in skeletal muscles. This is in tune with previous results obtained with other block copolymers for which the transfection properties seem to be dictated by the amphiphilic properties. All three polymers have better transfection efficiency than the reference polymer PE6400. This means that a positively charged amphiphilic block copolymer can be still an efficient vector for muscle transfection. It seems that it is even a better vector than non-hydrolysed ads068 at the same concentration ( $0.5 \% \mathrm{w} / \mathrm{w}$ solution). This type of 


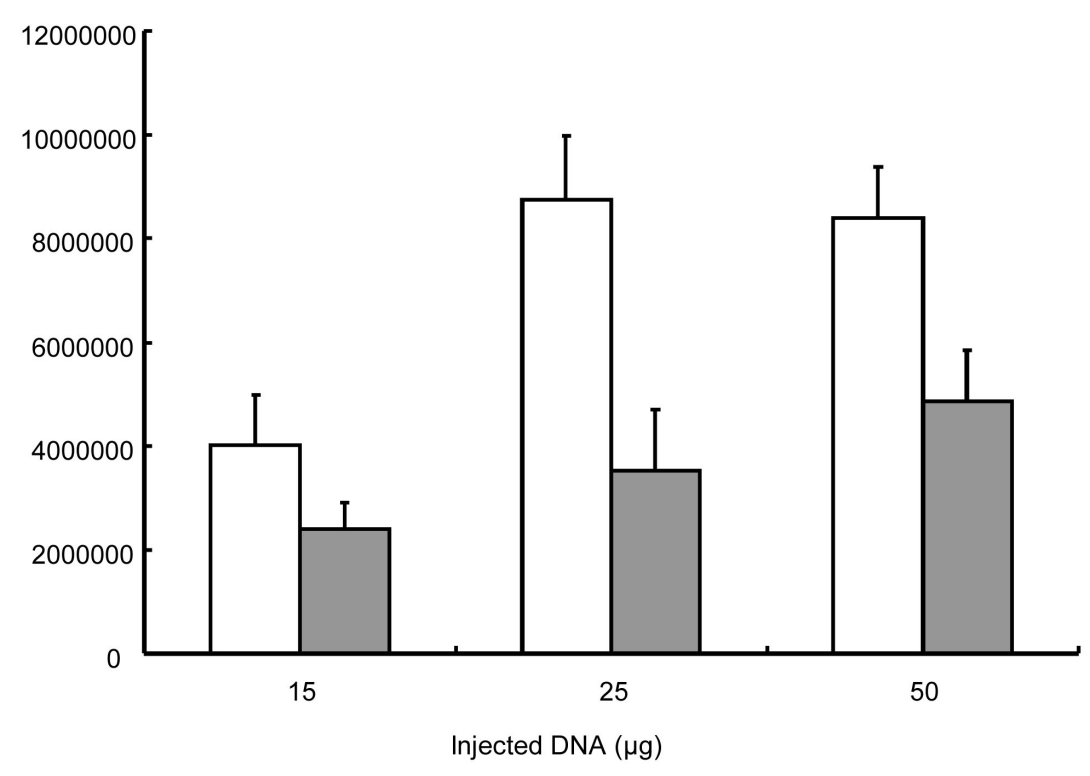

Figure 6. Luciferase expression in tibial anterior muscles with increasing quantity of DNA obtained with $0.1 \%$ concentration of poly(2-methyl-2-oxazoline-b-tetrahydrofurane-b-2-methyl-2-oxazoline) block copolymer (white bars) and 3\% Lutrol (grey bars) (luciferase $\mathrm{cps} / \mathrm{mg}$ units are used on the $\mathrm{Y}$-axis).

hydrolysed block copolymer is certainly worth of further investigation.

However, it can be questioned why polymer ADS 068 1B, hydrolysed 38\%, gave a rather good transfection in skeletal muscles (Figure 5) while it did not by intratracheal administration by microsprayer (Figure 7). This fact can be assigned to the different biological situations of the two assays. Many parameters can be involved, such as charge density on the polymer, local concentration upon contact, and different cell internalization pathways, among others, such as $\mathrm{pH}$ conditions, size of the nanoparticles obtained on DNA complexation, etc. More complete studies must be carried out to clear these points.

The influence of DNA concentration on luciferase expression in tibial anterior muscles obtained with 0.1 and 3\% Lutrol was also investigated. Figure 6 illustrates that the luciferase activity increased as the amount of naked DNA injected increased up to $50 \mu \mathrm{g}$.

The gene transfer efficiency to mice lungs was also investigated. Triblocks poly(2-methyl-2-oxazolineb-tetrahydrofurane-b-2-methyl-2-oxazoline) copolymer/DNA complexes were compared to that achieved with Lutrol used also for airway transfection. To that purpose a Chloramphenicol Acetyl Transferase reporter plasmid was formulated with Ads045, Ads052, Ads0681A, AdsO681B and Lutrol and injected intratracheally. After 2 days, airways were evaluated for reporter gene expression. Formulations containing 1\% - 3\% (w/v) Ads068 increased the expression of Chloramphenicol Acetyl Transferase by a factor of 3 to 4 when compared with Lutrol (Figure 7).

The experiments described in Figure 7 showed that Ads045 (0.1\%) and Ads068 1A (0.1\%) gave higher transfection efficiency for Chloramphenicol Acetyl Transferase by intratracheal administration than both Lutrol (3\%) or PE6400 (0.25\%). It is interesting to notice that these two polymers have a rather high molar ratio [hydrophilic units]/[hydrophobic units]. This observation may constitute a basis explaining the similar behavior for the block copolymers of the present study and Lutrol for which the same ratio is approximately 5.2. Of course, these two types of copolymer cannot be directly compared because of the different nature of their monomer units.

\section{Conclusion}

This preliminary work gave the information that the in vivo transfection efficiency of muscles and of pulmonary epithelium can be improved by changing the type of amphiphilic block copolymers. Some triblock copolymers poly(2-methyl-2-oxazoline-b-tetrahydrofurane-b-2-methyl-2-oxazoline) revealed having a better in vivo effi- 


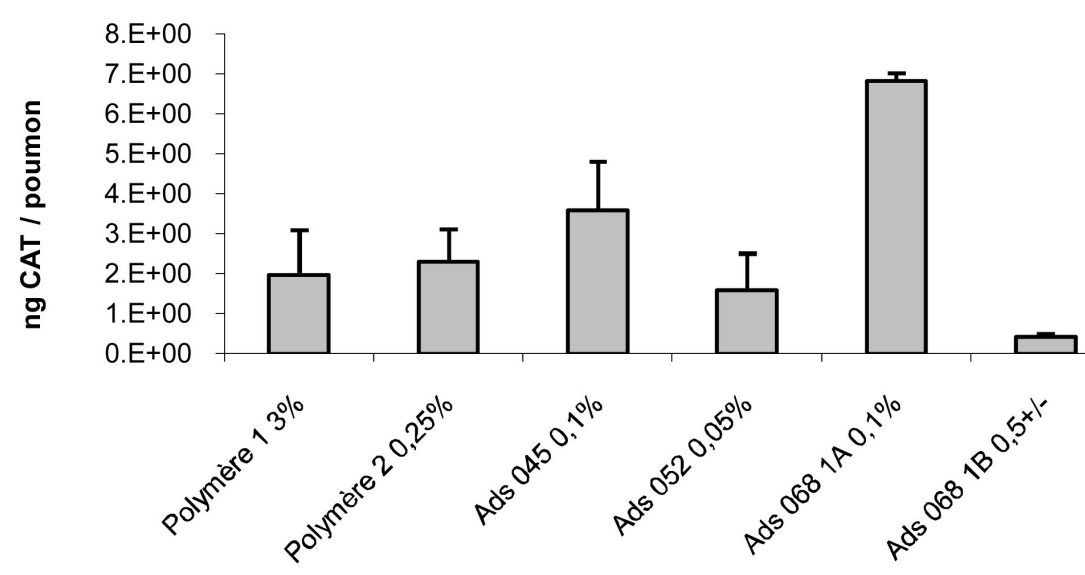

Figure 7. Chloramphenicol acetyl transferase (CAT) transfer efficiency (ng CAT/lung), using intratracheal administration by microsprayer of mice. Several polymers were used: Polymer 1 is Lutrol at a 3\% concentration, Polymer 2 is PE6400 poloxamer at a $0.25 \%$ concentration, Ads045, Ads052, Ads0681A and Ads0681B (the only copolymer being positively charged) are described in Table 1.

ciency than Lutrol or PE6400 which are the best vectors currently available. It also showed the specificity of different in vivo transfection assays since a partly charged copolymer (hydrolysed) showed noticeable properties of in vivo DNA transfection at least by muscle injection, in agreement with the efficiency exhibited by multiblocks poloxamines such as tetroniks ${ }^{\circledR}$ bearing positive charge in physiological conditions [13], while it exhibited poor transfer efficiency by direct intratracheal administration. This family of copolymer is filling the gap between the positively charged polyelectrolytes and the neutral amphiphilic block copolymers, opening new avenues for research on more efficient synthetic DNA vectors.

\section{Experimental}

\subsection{Animals}

Female Swiss and C57Bl6 mice were obtained at 8 weeks of age from Janvier (Le Genest Saint Isle, France).

\subsection{Materials}

All chemicals such as THF, 2-methyl-2-oxazoline (2-MeOx), acetonitrile, dichloromethane, (Aldrich), were dried on calcium hydride. Triflic anhydride, and diethylether were used as received. Lutrol is a triblock copolymer poly(ethylene oxide-b-propylene oxide-b-ethylene oxide) (Aldrich) poly(EO(76)-b-PO(29)-b-EO(76)), Mn $=8400$.

\subsection{Plasmids}

The plasmids pCMV-luc (Ferrari et al., 1997), and pCIK-CAT (generous gift of D. Gill, Oxford UK) (Pitard et al., 2001) contained luciferase and the chloramphenicol acetyl transferase (CAT) reporter genes controlled by the human cytomegalovirus immediate early gene promoter. Plasmids were purified from recombinant $E$. coli by means of EndoFree plasmid purification columns (Qiagen, Chatsworth, CA). Plasmid DNA purified following the instructions from Qiagen contains negligible amounts of endotoxin ( $<0.1 \mathrm{EU} / \mu \mathrm{g}$ plasmid).

\subsection{Polymer Synthesis}

Basically, the triblock synthesis was based on the procedure published by Goethals (Scheme 1) [11]. The polymerization of THF was realized at equilibrium at room temperature. Typically, $20 \mathrm{~mL}$ of dichloromethane were mixed with $20 \mathrm{~mL}$ of THF. $1.62 \mathrm{~g}$ of triflic anhydride was introduced with a syringe and the system was left for 4 hours. The system was quenched by $1.8 \mathrm{~mL}$ of 2-methyl-2-oxazoline (2-MeOx) diluted in $0.5 \mathrm{~mL}$ of THF. The system is then left at room temperature for 24 hours and can be sampled out for the sake of analysis. This sam- 
ple can be directly dried under vacuum before being analysed by NMR spectroscopy (Figure 8). The main product was dried under vacuum and $60 \mathrm{~mL}$ of dried acetonitrile were added at room temperature. When the polymer was dissolved, $10 \mathrm{~mL}$ of 2-methyl-2-oxazoline were introduced and the system was heated at $60^{\circ} \mathrm{C}$ for 24 hours. The polymerization yield of 2-MeOx was close to $100 \%$. After drying under vacuum, the polymer is a pale yellow solid. It can be dissolved in dichloromethane and precipitated in diethylether. After filtration and drying under vacuum $\left(36\right.$ hours at $30^{\circ} \mathrm{C}$ ) the polymer can be analysed by NMR spectroscopy.

\subsection{Polymer Characterization}

In order to check the point of the absence of homopoly (2-MeOx), a second purification of the polymer was carried out according to a method which has already been described elsewhere [12]. Briefly, this purification technique makes profit of the emulsifying properties of the block copolymer. The block copolymer was dissolved in $\mathrm{CHCl}_{3}$ and water was added. After vigorous stirring, the system decanted into three phases. The upper one was an aqueous solution which should contain mainly poly (2-methyl-2-oxazoline), as shown by the analysis of the residue after evaporation. The lowest one should be a solution of poly (THF) in chloroform, and the middle one was an emulsion which showed a tendency to aggregation, and containing the triblock. It was first shown that the chloroform solution only contained a negligible quantity of poly (THF). This was expected, due to the preliminary precipitation of the solution of the polymer in diethylether just after synthesis which eliminates poly(THF), as shown above. It was necessary to make sure that the poly (THF) detected on the NMR spectra was belonging to the block copolymer, and not due to homopoly (THF) as a side product. Thus, a mixture of 150 mg homopoly (THF) and $150 \mathrm{mg}$ of homopoly (2-methyl-2-oxazoline) was dissolved in $\mathrm{CH}_{2} \mathrm{Cl}_{2}$ and precipitated in diethylether according to the purification method used above. The insoluble fraction in diethylether amounted to $147 \mathrm{mg}$ and after analysis by ${ }^{1} \mathrm{H}$ NMR spectroscopy it was shown that it had a negligible content in poly(THF), thus validating the purification technique by precipitation in diethylether. The whole reaction scheme is shown

Proton NMR spectroscopy of polyTHF quenched by 2-Me-2-OX
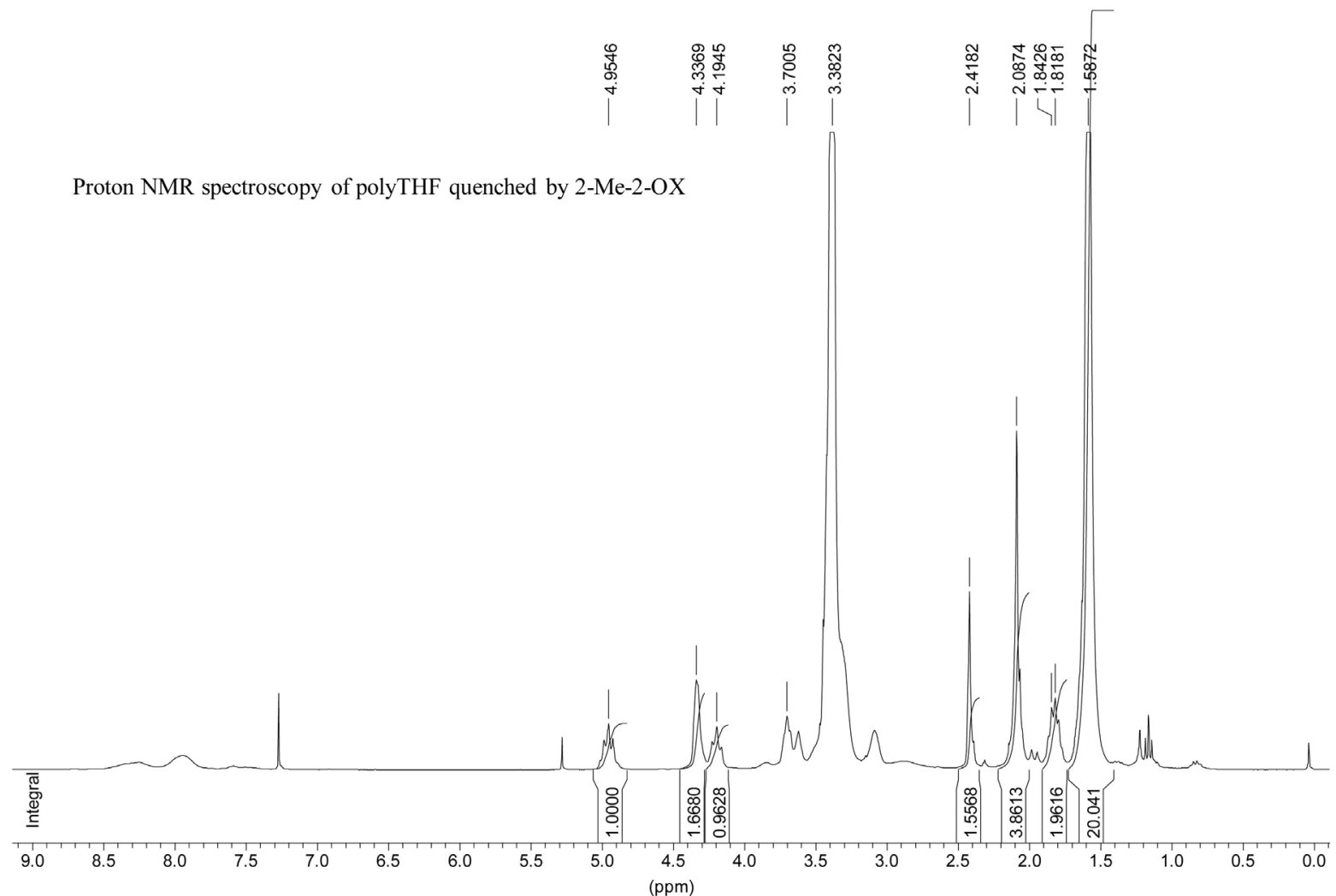

Figure 8. ${ }^{1} \mathrm{H}$ NMR spectrum of a poly(THF) terminated by quenching the polymerization by 2-methyl-2-oxazoline (ads052). Two protons of the oxazolinium rings are detected by NMR spectroscopy at $4.96 \mathrm{ppm}$ under the form of a triplet, and can be used to calculate the polymerization degree of the polyTHF oligomers obtained after quenching by 2-Me-Oxz. 
on scheme 1. It is worth noting that sampling after quenching the THF polymerization by 2-MeOx gives a polymer terminated by two oxazolinium ions the concentration of which can be measured by NMR spectroscopy.

On Figure 8, two protons of the oxazolinium rings are detected by NMR spectroscopy at $4.95 \mathrm{ppm}$ under the form of a triplet, and can be used to calculate the polymerization degree of the living polyTHF oligomers obtained after quenching by 2-Me-Ox. The aliphatic protons of the pTHF main chain can be seen at $1.59 \mathrm{ppm}$ and can be used to calculate with protons at $4.96 \mathrm{ppm}$ the polymerization degree of these oligomers assuming that there is no oxazolinium deactivation, for instance by adventitious moisture. The spectrum showed that there are some polyoxazoline units witnessed by the peak of the methyl groups belonging to these units at $1.84 \mathrm{ppm}$. They belong to homo-poly (2-MeOXZ) or to poly(THF) oligomers.

It is to be noted that, in principle, there is no transfer in this system, taking into account the absence of unsaturation of any kind in the range 5.0 to $7.0 \mathrm{ppm}$. It can be concluded that the 2-MeOx units are attached to the polymer. The polymerization of 2-MeOx gave a polymer the protonic spectrum of which is shown on Figure 1. On Figure 1, a trace of residual diethylether methyl group is observed at $1.20 \mathrm{ppm}$, and two protons of the oxazolinium rings are also detected by NMR spectroscopy at $4.97 \mathrm{ppm}$ under the form of a triplet, and can be used to calculate as above the polymerization degree of the oligomers obtained after the polymerization of 2-Me-Ox. The aliphatic protons of the pTHF main chain can be seen at $1.61 \mathrm{ppm}$ and can be used to calculate the polymerization degree of the pTHF block of the oligomers assuming that there is no oxazolinium deactivation. It can be surprising that the DP of the poly (THF) is lower than the expected one by the initial monomer composition of the reactants, even taking into account that the polymerization is an equilibrium. This is probably resulting from the fact that some depolymerization can be occuring on the living polymer during Me2-OX quench. For the determination of the average number molar mass, quantitative ${ }^{13} \mathrm{C}$ NMR spectroscopy was used. The spectrum is displayed on Figure 2. The peak at $21.43 \mathrm{ppm}$ is due to the methyl group of 2-MeOx units. The peak at 26.8 ppm is due to the aliphatic methylene carbons of the P(THF) units, The multiplet around $47.1 \mathrm{ppm}$ is to be assigned to the methylene carbons of the 2-MeOx units and the peak at $70.9 \mathrm{ppm}$ is due to the carbon of the $-\mathrm{CH}_{2} \mathrm{O}$ - of the $\mathrm{p}$ (THF) units. Integration of these peaks on gated spectra allows determining the structural characteristics of the triblock. The various measurements showed that the peak at $70.9 \mathrm{ppm}$ is a better indication of the Poly(THF) content than the peak at $28.6 \mathrm{ppm}$ for which there is often superimposition of small peaks due to impurities. An important observation is that the small peak at $23.2 \mathrm{ppm}$ is due to a methylene carbon of a p(THF) unit close to the first 2-MeOx unit of the of the neighboring block. While the accuracy of the determination of the value of its integration is not very high, it allows calculating an order of magnitude of the molar mass of the copolymer. This figure must be compared to the value of the molar mass which can be calculated from the ${ }^{1} \mathrm{H}$ NMR spectrum. Due to the fact that these two determinations are subject to large source of error, these values are to be averaged.

\subsection{Copolymer Hydrolysis}

Copolymers were hydrolysed under the following procedure over a varying reaction duration range: $2 \mathrm{~g}$ of triblock were dissolved in water $(26 \mathrm{~mL})$. A solution of conc $\mathrm{HCl}\left(1.37 \mathrm{~mL}, 16.44 \mathrm{mmol}, 24 \mathrm{eq}, \mathrm{C}_{\mathrm{H} 30^{+}}=0.6 \mathrm{M}\right)$ was added to the mixture and let under reflux for $1 \mathrm{~h}$. Then a solution of $5 \mathrm{~N} \mathrm{NaOH}(50 \mathrm{~mL})$ was introduced and the resulting mixture was stirred over a period of $1 \mathrm{~h}$. The solution was concentrated under reduced pressure to afford a white solid. Acetonitrile was added to the solution and filtration was carried out. The solvent was then evaporated, and a small volume of acetonitrile was reintroduced before precipitation in cold $\mathrm{Et}_{2} \mathrm{O}$. The precipitate was dried under vacuum and ${ }^{1} \mathrm{H}$ NMR allowed to measure a hydrolysis ratio. $\delta_{\mathrm{H}}\left(300 \mathrm{MHz}, \mathrm{H}_{2} 0\right) 1.59\left(\mathrm{CH}_{2}\right.$ PTHF), $2.03-2.11\left(\mathrm{NCOCH}_{3} \mathrm{PMeOx}\right), 2.67-2.77\left(\mathrm{CH}_{2}-\mathrm{NH}-\mathrm{CH}_{2}\right)$ and $3.48\left(\mathrm{CH}_{2}-\mathrm{O}-\mathrm{CH}_{2} \mathrm{PTHF}\right.$ and $\left.\mathrm{CH}_{2}-\mathrm{NCOCH}_{3}-\mathrm{CH}_{2} \mathrm{PMeOx}\right) \delta_{\mathrm{C}}\left(75 \mathrm{MHz}, \mathrm{H}_{2} \mathrm{O}\right)$ 19.8, 24.55, 42.26, 43.31, 44.31, 44.86, 45.49, 46.77, 47.9, 49.08, 69.28 and 173.6 (Figure 4, Table 1, ADS068 1B, 38\% Hydrolysed).

\subsection{Intratracheal Administration}

Swiss and C57Bl6 mice were anesthetized with ketamine $(70 \mathrm{mg} / \mathrm{kg})$ and xylazine $(15 \mathrm{mg} / \mathrm{kg})$ injection intraperitoneally. Following anesthesia, mice were sprayed in the trachea with formulated DNA using a MicroSprayer (PennCentury, Philadelphia, PA). At least, five mice were included in each experimental group for measurement of reporter gene expression. The volume delivered using the microsprayer was $100 \mu \mathrm{l}$. 


\subsection{Intramuscular Injection}

Anesthetized Swiss mice were injected into shaved tibial anterior as previously reported (Pitard et al., 2002). They received 50 microliters of the formulation containing $10 \mu \mathrm{g}$ DNA and various concentrations of triblock copolymers.

\subsection{Reporter Gene assay}

Mouse lungs or tibial anterior muscles were dissected, frozen in liquid nitrogen and homogenized in $1 \mathrm{ml}$ reporter lysis buffer (Roche Diagnostics, Mannheim, Germany) supplemented with a protease inhibitor cocktail (Roche Diagnostics). After centrifugation at 10,000 rpm for $5 \mathrm{~min}$, CAT and luciferase activities were measured from an aliquot of supernatant with Victor $^{2}$ (PerkinElmer, Les Ulis, France), using a CAT Elisa kit (Roche Diagnostics) or the luciferase assay system (Promega). Each lung or muscle extract was analyzed in duplicate. CAT activity was determined in $200 \mu \mathrm{l}$ of supernatant following the instructions of the supplier. A standard curve, prepared in standard sample buffer (Roche Diagnostics), was included to each microplate using the CAT enzyme standard kit. Luciferase acticity was assayed by measuring light emission after addition of $100 \mu \mathrm{l}$ luciferase substrate to $20 \mu \mathrm{l}$ of the supernatant. Protein content was measured with a bicinchoninic acid (BCA) protein assay kit.

\section{Acknowledgements}

"Vaincre la Mucoviscidose” and the "Association Française contre la Myopathie” are gratefully acknowledged for a support for this research. Dr. M. Sassatelli is also gratefully acknowledged for his kind help in sample preparation.

\section{References}

[1] Xia, G. and Leaf, H. (2012) Recent Advances in Nonviral Vectors for Gene Delivery. Accounts of Chemical Research, 45, 971-979. http://dx.doi.org/10.1021/ar200151m

[2] Meredith, A.M. and Eric, E.S. (2009) Nonviral Vectors for Gene Delivery. Chemical Reviews, 109, $259-302$. http://dx.doi.org/10.1021/cr800409e

[3] Toussignant, J.D., Gates, A.L., Ingram, L.A., Johnson, C.L., Nietupski, J.B., Cheng, S.H., Eastman, S.J. and Scheule, R.K. (2000) Comprehensive Analysis of the Acute Toxicity Induced by Systemic Administration of Cationic Lipid:Plasmid:DNA Complexes in Mice. Human Gene Therapy, 11, 2493-2513. http://dx.doi.org/10.1089/10430340050207984

[4] Brissault, B., Leborgne, C., Guis, C., Danos, O., Cheradame, H. and Kichler, A. (2006) Linear Topology Confers in Vivo Gene Transfer Activity to Polyethylenimines. Bioconjugate Chemistry, 17, 759-765. http://dx.doi.org/10.1021/bc050287v

[5] Cheradame, H., Brissault, B., Guis, C., Guégan, P., Pomel, C., Kichler, A., Gau, J. and Auvray, L. (2006) Improvement of Synthetic Vectors for Gene Therapy Using Ring-Opening Cationic Polymerization. Macromolecular Symposia, 240, 166-177.

[6] Brissault, B., Kichler, A., Leborgne, C., Danos, O., Cheradame, H., Gau, J., Auvray, L. and Guis, C. (2006) Synthesis, Characterization, and Gene Transfer Application of Poly(ethylene glycol-b-ethylenimine) with High Molar Mass Polyamine Block. Biomacromolecules, 7, 2863-2870.

[7] Behr, J.P. (2012) Synthetic Gene Transfer Vectors II: Back to the Future. Accounts of Chemical Research, 45, 980-984. http://dx.doi.org/10.1021/ar200213g

[8] Bromberg, L., Alakhov, V.Y. and Hatton, T.A. (2006) Self-Assembling Pluronic-Modified Polycations in Gene Delivery. Current Opinion in Colloid and Interface Science, 11, 217-223. http://dx.doi.org/10.1016/j.cocis.2006.07.001

[9] Pitard, B., Pollard, H., Agbulut, O., Lambert, O., Vilquin, J.T., Cherel, Y., Abadie, J., Samuel, J.L., Rigaud, J.L., Menoret, S., Anegon, I. and Escande, D. (2002) Nonionic Amphiphile Agent Promotes Gene Delivery in Vivo to Skeletal and Cardiac Muscles. Human Gene Therapy, 13, 1767-1775. http://dx.doi.org/10.1089/104303402760293592

[10] Merdan, T., Kopecek, J. and Kissel, T. (2002) Prospects for Cationic Polymers in Gene and Oligonucleotide Therapy against Cancer. Advanced Drug Delivery Reviews, 54, 715-758. http://dx.doi.org/10.1016/S0169-409X(02)00046-7

[11] De Witte, I.C. and Goethals, E.J. (1999) Synthesis and Block Specific Complexation of Poly(ethylene oxide)-poly(tetrahydrofuran)-poly(ethylene oxide) Triblock Copolymers. Polymers for Advanced Technologies, 10, 287-292. http://dx.doi.org/10.1002/(SICI)1099-1581(199905)10:5<287::AID-PAT877>3.0.CO;2-F

[12] Cheradame, H., Pomel, C., Sassatelli, M., Sanh, A., Gau, J., Bacri, L., Auvray, L. and Guégan, P. (2008) Tuning Macro- 
molecular Structure of Synthetic Vectors for Gene Therapy. Macromolecular Symposia, 261, 167-181. http://dx.doi.org/10.1002/masy.200850122

[13] Pitard, B., Bello-roufai, M., Lambert, O., Richard, P., Desigaux, L., Fernandes, S., Lanctin, C., Pollard, H., Eeghal, M., Rescan, P.Y. and Escande, D. (2004) Negatively Charged Self-Assembling DNA/Poloxamine Nanospheres for in Vivo Gene Transfer. Nucleic Acids Research, 32, e159. http://dx.doi.org/10.1093/nar/gnh153 